Gut, 1979, 20, 499-503

\title{
Absorption studies in patients six to 10 years after construction of ileostomy reservoirs
}

\author{
L. O. NILSSON, H. ANDERSSON, L. HULTÉN, R. JAGENBURG, N. G. KOCK, \\ H. E. MYRVOLD, AND B. PHILIPSON
}

From the Department of Surgery II, the Department of Clinical Chemistry, and the Institution of Clinical Nutrition, Sahlgrenska Sjukhuset, University of Göteborg, Göteborg, Sweden

SUMMARY The absorption of fat, bile salts, and vitamin $\mathbf{B}_{12}$ was studied in 14 proctocolectomised patients six to 10 years after construction of a continent ileostomy. All patients were in excellent health and displayed no signs of malnutrition. Schilling test disclosed subnormal absorption of vitamin $B_{12}$ in one patient and borderline values in five. Faecal loss of bile acid was increased in 12 patients and fat malabsorption occurred in two. Except for slightly pathological liver tests in two patients, routine laboratory tests, including plasma concentration of vitamin $\mathrm{B}_{12}$ and folic acid, were normal. There were no signs of sodium or potassium depletion.

In 1969 the continent ileostomy was introduced as an alternative to the conventional ileostomy (Kock, 1969). Since then the method has been modified several times because of difficulties in maintaining perfect continence in some of the patients. An extensive review of the development of the method, experimental background and functional results, has recently been published (Kock et al., 1977). The functional results were good and the physical health of the patients excellent. There is, however, a general lack of knowledge concerning long-term metabolic effects of the ileal pouch.

The construction of a reservoir of the terminal part of the ileum results in stagnation of the intestinal contents in the pouch for several hours. The bacterial flora of effluents from the reservoir has been found to be intermediate between those from a conventional ileostomy and those from normal stools (Brandberg et al., 1972). The mucosal morphology was altered, with an increased cell turnover and shortening of the villi (Philipson et al., 1975). These findings might indicate that absorption disturbances would appear in the long run.

Absorption studies of fat, $d$-xylose, phenylalanine, and vitamin $B_{12}$ have been performed in patients with ileostomy reservoirs within two years after the construction of the reservoir. In these studies only marginal absorptive impairment was found and there was no significant difference between patients with ileostomy reservoirs and patients with conventional ileostomies (Jagenburg et al., 1971, 1975).

Received for publication 4 January 1979
Since the long-term metabolic consequences are known only to a limited extent, the present study was designed to evaluate intestinal absorption in patients with continent ileostomy six to 10 years after operation. Taking into account the altered bacterial flora and the altered mucosal morphology of the reservoir, and in view of the fact that the reservoir is constructed from the terminal ileum, we decided to focus our interest on the absorption of vitamin $B_{12}$, bile salts, and fat.

\section{Methods}

At the time of the investigation 46 patients, who had been operated with proctocolectomy and continent ileostomy at our hospital because of ulcerative colitis or polyposis of the colon, had been observed for more than six years. Of these patients 16 lived in the neighbourhood of Gothenburg and were asked to take part in the study. Two patients refused to participate because of their work. The group studied was thus confined to 14 patients, seven women and seven men. Clinical details of the patients are summarised in the Table. The mean age was 45 years (range 22-63 years). The patients were all in good general health and none showed signs of malnutrition. They were hospitalised for 12 days during the study. Routine laboratory tests were performed before the absorption tests. During the second day of hospitalisation the urine was collected and urinary electro. lytes determined.

Thirteen patients with conventional ileostomies after proctocolectomy because of ulcerative colitis 
Table Patients with ileostomy reservoirs

\begin{tabular}{|c|c|c|c|c|c|c|}
\hline Patient no. & $\operatorname{Sex}$ & Age $(y r)$ & $\begin{array}{l}\text { Interval since } \\
\text { operation }(y r)\end{array}$ & Type of outlet & Need of appliance & Ileal resection $(\mathrm{cm})$ \\
\hline 1 & $\mathbf{F}$ & 52 & 10 & $\mathbf{A}$ & & 4 \\
\hline 3 & $\mathbf{M}$ & 48 & 8 & $\mathbf{N}$ & & 7 \\
\hline 4 & $\mathbf{F}$ & 34 & 8 & $\mathbf{A}$ & & 5 \\
\hline 5 & $\mathbf{F}$ & 54 & 8 & $\mathbf{A}$ & & 3 \\
\hline 6 & $\mathbf{M}$ & 63 & 8 & A & + & 12 \\
\hline 8 & $\mathbf{M}$ & 41 & 7 & $\mathbf{N}$ & & 15 \\
\hline 9 & $\mathbf{M}$ & 22 & 7 & A & & 4 \\
\hline 10 & $\mathbf{F}$ & 31 & 10 & $\mathbf{A}$ & & 10 \\
\hline 11 & $\mathbf{M}$ & 40 & 7 & I & & 4 \\
\hline 12 & $\mathbf{F}$ & 55 & 6 & I & + & 12 \\
\hline 13 & $\mathbf{M}$ & 43 & 6 & $\mathbf{N}$ & & 5 \\
\hline 14 & $\mathbf{F}$ & 28 & 6 & I & & 4 \\
\hline
\end{tabular}

Indication for operation was familial polyposis in patient no. 9 and ulcerative colitis in the others. A: antiperistaltic outlet, I: isoperistaltic outlet, $\mathrm{N}$ : nipple valve outlet.

served as a control group in the determinations of faecal excretion of ${ }^{14} \mathrm{C}$-cholic acid. This group consisted of five women and eight men with a mean age of 33 years (range 21-59 years).

All patients gave their informed consent to participation.

\section{VITAMIN B12 ABSORPTION}

Vitamin $B_{12}$ absorption was determined by use of the Schilling test as modified by Gräsbeck et al. (1956). Separate 24 hour urinary collections were made on two days. The tests were done without administration of intrinsic factor. The amount of radioactive vitamin $B_{12}$ in the urine during the first 24 hours was expressed in per cent of the oral dose. Urinary excretion exceeding $10 \%$ in 24 hours was considered normal and excretions between 5 and $10 \%$ borderline values.

\section{FAECAL FAT EXCRETION}

The standard hospital diet contains about $75 \mathrm{~g}$ of fat per day. In order to make defective absorption of fat more obvious, the patients were given 0.21 of cream containing about $75 \mathrm{~g}$ of fat in addition to the standard diet for three consecutive days. Ileostomy contents were collected during this period. The weight was recorded and the fat content determined by the method described by van de Kamer et al. (1949). According to Losowsky et al. (1974), the faecal fat is influenced by the magnitude of the fat intake and should not exceed $7 \%$ of the oral intake. On this basis, faecal excretion of $10 \mathrm{~g}$ per day was used as the upper limit of normal.

FAECAL EXCRETION OF ${ }^{14}$ C-CHOLIC ACID After an overnight fast, $10 \mu \mathrm{Ci}$ of ${ }^{14} \mathrm{C}$-cholic acid (New England Nuclear, specific activity $44.5 \mathrm{mCi}$ / mmol) was injected during about five minutes via the tubing of an intravenous glucose infusion set. The bile salts were cleaned from the syringe with additional glucose. During the first 24 hour period, the ileostomy effluents were collected by intermittent intubation of the reservoir. Twenty-four hours later each patient was given an oral dose of carmine red. At the same time the reservoir was intubated and the tube left in the reservoir for continuous drainage. Collection of effluents was continued until carminecoloured effluent appeared. The total amount of faeces collected from the time of injection until appearance of changed faecal colour was homogenised with water and DNS as faecal softener. After homogenisation three samples, each of $0.250 \mathrm{~g}$, were digested for five hours at $+55^{\circ} \mathrm{C}$ with $2 \mathrm{ml}$ Protosol (New England Nuclear) in glass counting vials. For decolourisation, $0.5 \mathrm{ml}$ of freshly prepared $20 \%$ benzoyl peroxide in toluene was added and heated for 30 minutes at $+55^{\circ} \mathrm{C}$. The bleached samples were cooled and a few drops of glacial acetic acid were added to decrease chemiluminescence. Ten millilitres of a scintillation liquid (6.6 g Permablend in $1.000 \mathrm{ml}$ toluene) and $0.1 \mathrm{ml}$ methanol were added. The radioactivity was determined by means of the liquid scintillation technique (Tri-Carb, Packard, Model 3320) using an internal standard. The radioactivity of the total faecal homogenates, calculated as the percentage of the radioactivity injected, was assumed to express the fraction of the bile salts that had escaped the enterohepatic circulation during a 24hour period.

This method gave an error of a single determination within $5 \%$ when calculated from triple analysis on 83 samples (within the range of $10-0.5 \mu \mathrm{Ci}$ ). The mean recovery of $6.25 \mu \mathrm{Ci}$ Carboxyl-14C-cholic acid added to faeces was $99 \%$ (SD $4.7 \%$ ) in 24 determinations. The mean recovery in faeces of the injected ${ }^{14} \mathrm{C}$-labelled bile salts was $100 \%$ (SD $8.5 \%$ ) 
in 18 studies when stools were analysed until they were free from radioactivity. According to previous studies at our laboratory, a faecal loss of more than $20 \%$ of the dose administered intravenously was considered abnormal (Andersson et al., 1978). In 16 control patients (nine women and seven men, mean age 36 years) who were considered normal where small bowel function was concerned, a mean faecal loss of $5 \cdot 8 \%$ (range $1-14 \%$ ) was found.

\section{ANALYSIS OF BLOOD SAMPLES}

Haemoglobin, erythrocyte sedimentation rate (ESR), liver function tests, serum concentrations of electrolytes, creatinine, albumin, protein, iron and total iron binding capacity (TIBC) were determined by routine laboratory techniques. Vitamin $B_{12}$ in plasma was determined by a microbiological method using Euglena gracilis (Hutner et al., 1956), reference range $135-735 \mathrm{pmol} / \mathrm{l}$. Folate in plasma and blood was assayed with Lactobacillus casei, according to the technique described by Hansen (1964). Measured by this method, the reference range of folate is 4-35 $\mathrm{nmol} / 1$ in plasma and $100-450 \mathrm{nmol} / 1$ in blood.

\section{URINE ANALYSIS}

During a 24 hour period the urinary excretion of sodium (reference range $50-150 \mathrm{mmol} / \mathrm{l}$ ) and potassium (reference range $50-150 \mathrm{mmol} / \mathrm{l}$ ) was measured. The reference values from our laboratory refer to persons with intact colons. According to Gallagher et al. (1962) the range of sodium excretion in the urine in conventional ileostomies is $1-250 \mathrm{mmol} /$ day (mean $70 \mathrm{mmol} /$ day) and of potassium 28-90 $\mathrm{mmol} /$ day (mean $78 \mathrm{mmol} /$ day).

\section{Results}

In one patient ESR was $23 \mathrm{~mm} / \mathrm{h}$ (reference limit $<13 \mathrm{~mm} / \mathrm{h}$ ) and serum bilirubin $29 \mathrm{mmol} / \mathrm{l}$ (reference value $3 \cdot 4-21 \mathrm{mmol} / \mathrm{l})$. ALAT was slightly raised (1.0 $\mu$ cat $/ 1$, reference limit $<0.7$ ) in another patient. Apart from these two exceptions, ESR and liver function tests were normal in all patients. Haemoglobin, serum electrolytes, creatinine, albumin, and protein were normal in all patients. In one male patient a borderline value $(14 \mu \mathrm{mol} / \mathrm{l}$, reference limit $>15$ $\mu \mathrm{mol} / \mathrm{l})$ of serum iron was found. TIBC was normal in all patients.

The Schilling test was below $5 \%$ in one patient, who had had an ileal resection of about $10 \mathrm{~cm}$. Borderline values-that is, values between 5 and $10 \%$-were obtained in five patients, whereas the remaining eight patients had a normal excretion, above $10 \%$. (During the second 24 hour period all patients had only negligible amounts of radioactivity in the urine.) Two patients, one with a Schilling test below $5 \%$ and another with a normal Schilling test, had vitamin $\mathbf{B}_{12}$ substitution therapy. All patients had normal values of vitamin $B_{12}$ in plasma. The values of folate in plasma and in blood were normal in all patients.

The range of faecal fat excretion was 4-30 g/24 h. Twelve patients had faecal fat below $10 \mathrm{~g} / 24 \mathrm{~h}$, whereas two patients had abnormal excretions of 16 and $30 \mathrm{~g} / 24 \mathrm{~h}$ respectively. The mean weight of the intestinal discharge during the high fat diet period was $830 \mathrm{~g} / 24 \mathrm{~h}$.

The mean faecal excretion of ${ }^{14} \mathrm{C}$-cholic acid was $46 \%$ (range $12-92 \%$ ) in the reservoir group compared with $17 \%$ (range $5-33 \%$ ) in the group with conventional ileostomies during a 24 hour period of enterohepatic circulation (Fig. 1). The difference is statistically significant $(P<0.01$, Wilcoxon-Test).

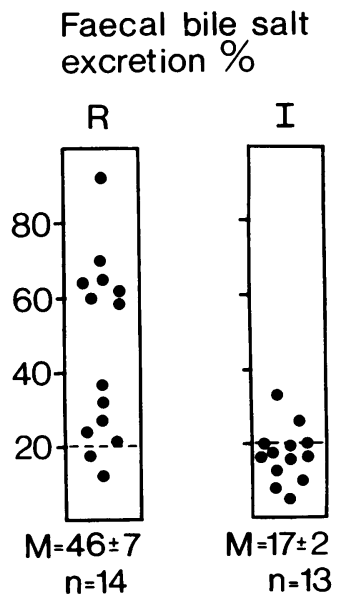

Fig. 1 Faecal excretion of intravenously administered ${ }^{14} C$ - cholic acid in patients with ileostomy reservoirs $(R)$ and in patients with conventional ileostomies $(I)$.

All reservoir patients except two had values exceeding $20 \%$ of the administered dose. There was no correlation between the cholic acid excretion and the faecal fat excretion (Fig. 2). The faecal excretion of ${ }^{14} \mathrm{C}$-cholic acid was not correlated with the vitamin $\mathrm{B}_{12}$ absorption, as measured by the Schilling test.

The urinary sodium excretion was above $20 \mathrm{mmol} /$ $24 \mathrm{~h}$ in all patients and the mean value was $60 \mathrm{mmol} /$ $24 \mathrm{~h}$ (Fig. 3). The mean value for urinary potassium excretion was $74 \mathrm{mmol} / 24 \mathrm{~h}$ and the mean urinary volume $1 \cdot 31 / 24 \mathrm{~h}$.

\section{Discussion}

The terminal ileum is the specific site of active absorption of vitamin $B_{12}$ (Booth and Mollin, 1959) and of bile salts (Dietschy, 1968). Absorption of 


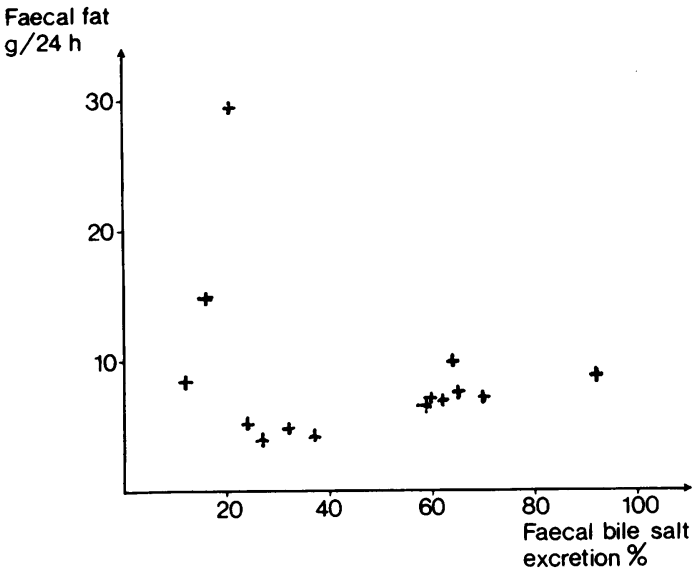

Fig. 2 Faecal fat in relation to faecal excretion of ${ }^{14} \mathrm{C}$-cholic acid in patients with ileostomy reservoirs.

Urinary electrolytes $\mathrm{mmol} / 24 \mathrm{~h}$

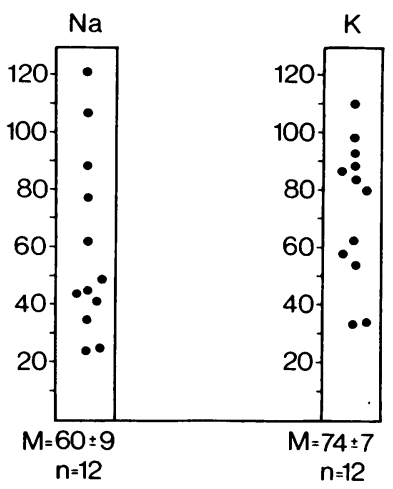

Fig. 3 Urinary excretion of sodium and potassium in patients with ileostomy reservoirs. Mean and range for patients with conventional ileostomies (Gallagher et al., 1962): Na $70 \mathrm{mmol} /$ day (1-250), K $78 \mathrm{mmol} /$ day (28-90).

vitamin $B_{12}$ and of bile salts is influenced not only by the function of the mucosa but also by the bacteria in the intestinal contents. Several bacteria, and particularly anaerobic Bacteriodes, are known to have the ability to deconjugate bile salts and thereby influence their absorption (Drasar et al., 1966; Hill and Drasar, 1968). Absorption of vitamin $B_{12}$ is also impaired by bacterial overgrowth of the bowel (Gorbach and Tabaqchali, 1969). Thus, it seems possible that absorption of vitamin $B_{12}$ and bile salts might be impaired in patients with an ileum reservoir. On the other hand, investigations by Jagenburg et al. (1975) and Gadacz et al. (1977) have shown that, among other substances, vitamin $B_{12}$, together with intrinsic factor, is absorbed from the reservoir if instilled locally. They postulated that the prolonged time of contact between the mucosa and the intestinal contents in the reservoir might improve absorption. In the present series borderline values (5-10\% excretion) for the Schilling test were found in five patients but a subnormal value $(<5 \%$ excretion) in only one patient. The low incidence of vitamin $B_{12}$ malabsorption is of the same order of magnitude as in patients with conventional ileostomies (Miettinen and Peltokallio, 1971). The results agree with those of Jagenburg et al. $(1971,1975)$, who found no significant difference of vitamin $\mathbf{B}_{12}$ absorption in patients with ileum reservoirs and patients with conventional ileostomies. A higher frequency of vitamin $B_{12}$ malabsorption in patients with reservoirs than in patients with conventional ileostomies has, however, been reported by Schjønsby et al. (1977), who found Schilling tests below $8 \%$ in five patients out of seven with continent ileostomies and in two out of seven with conventional ileostomies. Since they were able to improve vitamin $\mathbf{B}_{12}$ absorption by antibiotic treatment, they concluded that vitamin $\mathbf{B}_{12}$ absorption was impaired in patients with continent ileostomies owing to the altered bacterial flora in the reservoir. In the present series, borderline Schilling test values were found in five patients. This might indicate a slight impairment of vitamin $B_{12}$ absorption. However, in none of these patients were subnormal plasma levels of vitamin $B_{12}$ found six to 10 years after operation. There is thereforegenerally no need for vitamin $\mathbf{B}_{12}$ substitution in patients with continent ileostomies, but repeated postoperative determinations of plasma $\mathbf{B}_{12}$ are recommended.

The loss of cholic acid was increased in 12 patients. Since only the total faecal loss of cholic acid was measured, no conclusions can be drawn as to whether the impaired absorption is caused by bacterial deconjugation of the cholic acid or by impaired absorptive capacity of the intestinal mucosa. There was no correlation between faecal loss of cholic acid and faecal fat excretion. Two patients had fat malabsorption, but these patients had only slightly increased faecal losses of cholic acid. On the other hand, patients with great losses of cholic acid had normal fat absorption as evaluated by determination of faecal fat. The cause of fat malabsorption in two patients has not been established, but bacterial overgrowth, inducing increased bacterial deconjugation of cholic acid in the jejunum, might be responsible. Rapid passive absorption of unconjugated bile acid in this part of the intestine (Dietschy, 1968; Heaton, 1969) might lead to insufficient micelle formation and fat malabsorption.

Patients with conventional ileostomies have a 
reduced urinary output of sodium compared with normal controls (Gallagher et al., 1962). In that study 15 ileostomy patients were found to have a mean urinary output of $70 \mathrm{mmol}$ sodium per day, and five patients had urinary sodium output of less than $10 \mathrm{mmol} /$ day. According to Hill (1976), clinical signs of sodium depletion are practically absent when the urinary output is above $10 \mathrm{mmol} /$ day. In the present series the mean sodium output was $60 \mathrm{mmol} /$ day and no patient had a sodium output of less than $20 \mathrm{mmol} / \mathrm{day}$. The findings suggest that the net sodium absorption from the gastrointestinal tract in patients with ileostomy reservoirs is of the same order of magnitude as in patients with conventional ileostomies, thus indicating sodium absorption from the ileal pouch. This would be in accordance with the findings of Gadacz et al. (1977), who studied net absorption of sodium and chloride ions in ileum reservoirs and recorded absorption against large concentration gradients.

The excellent health of the patients six to 10 years after construction of the ileal pouch indicates that the ileal pouch as such does not cause serious metabolic disturbances or malabsorption. This assumption was confirmed by the laboratory and absorption tests performed in this study. Although borderline values of the Schilling tests were found in several patients, and faecal loss of bile acid was increased in most of the patients, the metabolic consequences of the ileal pouch do not seem to differ significantly from those of the conventional ileostomy.

This work was supported by grants from the Medical Research Council (Proj. No B79-17X-00577-15B and No B79-17X-03117-09.

\section{References}

Andersson, H., Filipsson, S., and Hultén, L. (1978). Determination of the faecal excretion of labelled bile salts after i.v. administration of ${ }^{14} \mathrm{C}$-cholic acid. Scandinavian Journal of Gastroenterology, 13, 249-255.

Booth, C. C., and Mollin, D. L. (1959). The site of absorption of vitamin $\mathrm{B}_{12}$ in man. Lancet, 1, 18-21.

Brandberg, $\AA .$, Kock, N. G., and Philipson, B. (1972). Bacterial flora in intraabdominal ileostomy reservoir. Gastroenterology, 63, 413-416.

Dietschy, J. M. (1968). Mechanisms for the intestinal absorption of bile acid. Journal of Lipid Research, 9, 297309.
Drasar, B. S., Hill, M. J., and Shiner, M. (1966). The deconjugation of bile salts by human intestinal bacteria. Lancet, 1, 1237-1238.

Gadacz, T. R., Kelly, K. A., and Phillips, S. F. (1977). The continent ileal pouch: absorptive and motor features. Gastroenterology, 72, 1287-1291.

Gallagher, N. D., Harrison, D. D., and Skyring, A. P. (1962). Fluid and electrolyte disturbances in patients with longestablished ileostomies. Gut, 3, 219-223.

Gorbach, S. L., and Tabaqchali, S. (1969). Bacteria, bile, and the small bowel. Gut, 10,963-972.

Gräsbeck, R., Nyberg, W., and Siurala, M. (1956). Urinary excretion of radioactive vitamin $B_{12}$ ("Schilling test"). (Swedish). Nordisk Medicin, 56, 1656-1658.

Hansen, H. S. (1964). On the Diagnosis of Folic Acid Deficiency. Thesis: Göteborg.

Heaton, K. W. (1969). The importance of keeping bile salts in their place. Gut, 10, 857-863.

Hill, G. L. (1976). Ileostomy: Surgery, Physiology and Management. Grune and Stratton: New York.

Hill, M. J., and Drasar, B. S. (1968). Degradation of bile salts by human intestinal bacteria. Gut, 9, 22-27.

Hutner, S. H., Bach, M. K., and Ross, C. I. M. (1956). A sugar-containing basal medium for vitamin $\mathrm{B}_{12}$-assay with Euglena; application to body fluids. Journal of Protozoology, 3, 101-112.

Jagenburg, R., Dotevall, G., Kewenter, J., Kock, N. G., and Philipson, B. (1971). Absorption studies in patients with "intraabdominal ileostomy reservoirs" and in patients with conventional ileostomies. Gut, 12, 437-441.

Jagenburg, R., Kock, N. G., and Philipson, B. (1975). Vitamin $B_{12}$-absorption in patients with continent ileostomy. Scandinavian Journal of Gastroenterology, 10, 141144.

Kamer, van de, J. H., ten Bokkel Huinink, H., and Weyers, H. A. (1949). Rapid method for determination of fat in feces. Journal of Biological Chemistry, 177, 347-355.

Kock, N. G. (1969). Intra-abdominal "reservoir" in patients with permanent ileostomy. Archives of Surgery, 99, 223231.

Kock, N G., Darle, N., Hultén, L., Kewenter, J., Myrvold, H., and Philipson, B. (1977). Ileostomy. Current Problems in Surgery, 14 (8), 1-52.

Losowsky, M. S., Walker, B. E., and Kelleher, J. (1974). Malabsorption in Clinical Practice. Churchill Livingstone: Edinburgh.

Miettinen, T. A., and Peltokallio, P. (1971). Bile salt, fat, water, and vitamin $\mathbf{B}_{12}$ excretion after ileostomy. Scandinavian Journal of Gastroenterology, 6, 543-552.

Philipson, B., Brandberg, Å., Jagenburg, R., Kock, N. G., Lager, I., and Åhrén, C. (1975). Mucosal morphology, bacteriology and absorption in intraabdominal ileostomy reservoir. Scandinavian Journal of Gastroenterology, 10, 145153.

Schjønsby, H., Halvorsen, J. F., Hofstad, T., and Hovdenak, N. (1977). Stagnant loop syndrome in patients with continent ileostomy (intra-abdominal ileal reservoir). Gut, 18, 795-799. 